\title{
Psychological Impact of the COVID-19 Pandemic on Nurses Employed by the Palestinian Ministry of Health in Gaza
}

\author{
Abdalkarim Said Radwan \\ Faulty of Nursing, Islamic University of Gaza \\ Gaza, Gaza Strip, Palestine \\ Email: arodwan [AT] iugaza.edu.ps
}

\begin{abstract}
-
Introduction: Coronaviruses hit the world at the end of 2019, but the first two cases inGaza Strip were diagnosed on 21 March in the quarantine centers. Nurses working with infected or suspected cases are at high risk to get the disease which may generate anxiety among them. Therefore, this study aimed to assess the psychological impact of COVID-19 pandemic on Palestinian nurses employed by the Palestinian Ministry of Health in Gaza Strip, Palestine.

Materials and methods: A toal of 424 nurses completed an online questionnaire packet that included demographic data and the 7-item Generalized Anxiety Disorder Scale (GAD-7).

Results: Results from this study revealed that while only $22.4 \%$ of the participants worked at quarantine centers designated to take care of infected/suspected cases of COVID-19, but a huge number of them (77.6\%) got in direct contact with infected people. Variant levels of anxiety were reported by participants with $35.4 \%$ of them having mild, $23.6 \%$ moderate and $13.4 \%$ severe levels of anxiety while $27.6 \%$ did not manifest anxiety.

Factors contributed to the level of anxiety include having a family member diagnosed with COVID-19, a family member died with COVID-19 and getting in direct contact with people infected/ suspected to have COVID-19.

Conclusions and implications for practice: The high level of exposure to contamination of Corona virus represent risk factor of nurse's fear and anxiety through their contact with patients, friends, relatives and family members. Psychosocial support programs as setting channels of one-to-one online or phone counseling for nurses may be effective to alleviate negative psychological effects and to enhance the mental health of nurses.
\end{abstract}

Keywords---- Nurses, Psychological impact, COVID-19, GAD-7.

\section{INTRODUCTION}

Coronaviruses (COVID-19), a novel that cause of a cluster of pneumonia cases at the end of 2019. The infection started in Wuhan in China, then it rapidly it became a pandemic. The World Health Organization (WHO) declared the disease COVID-19 as a pandemic in February 2019 [1]. Mortality related to COVID-19 is estimated to be around $2 \%$ among overall ages, but it ranges from $0.2 \%$ in people under 50 to $14.8 \%$ in those who are over 80 years. Moreover, mortality rate is higher among people diagnosed with chronic comorbid health conditions [2]. Up to the $5^{\text {th }}$ of March, 2020, Palestine was free of Corona virus. On the $6^{\text {th }}$ of March, seven cases were found to be positive for COVID-19 in Bethlehem City in the West Bank [3]. These cases were diagnosed among a hotel staff who were in contact with a group of Greek tourists who had visited the city in late February. The first two cases in the Gaza Strip were diagnosed in a quarantine center on $21^{\text {st }}$ of March, 2020 among two Palestinians who were traveling abroad and returned to the Gaza Strip. On August 24, 2020, confirmed cases outside of quarantine centers were recorded. As a consequence, a complete lock down of the Gaza Strip was imposed [3].

Gaza Strip is a small territory of $365 \mathrm{~km} 2$ with about two million inhabitants. It is located on the Eastern Mediterranean coast and belongs to the self-governing territories of Palestine. For over than14 years, no free movement is possible in and out of the Gaza Strip [4]. The Palestinian MoH is the main provider for health services and manages most of the hospitals in the Gaza Strip. There are 81 available hospitals in Palestine; 51 in the West Bank, including East Jerusalem and 30 hospital in in Gaza Strip. As of 2017, the total bed capacity was 6,146. However, due to closure policies imposed by Israel against Gaza Strip, the $\mathrm{MoH}$ face many problems in running the health sector in Gaza since it became difficult to purchase pharmaceuticals, medical equipment and supplies. As a result, the MoH having to overpay for medicines, or rely on Israeli control of import medical equipment and supplies, including important materials such as mechanical ventilators, medication, testing kits for COVID-19 and personal protection equipment (PPE). This shortage of supply had negatively impacted the provision of health care services and the preparedness for health care professional to develop and implement plans to control the spread of COVID-19 and to provided treatment for other diseases [5].

Gaza Strip has a very high density as about two million people live in a about 360 square kilometer. With the high levels of poverty that prevails among inhabitant of the Gaza Strip, people living in Gaza are highly vulnerable to 
contagion [6]. Health experts in the Gaza Strip are sounding the alarm as the pandemic could soon be out of control. Hospitals there are unequipped and unprepared for such a situation. After much effort, the Gaza Health Ministry was recently able to increase the number of hospital beds dedicated to COVID-19 patients from 100 to 150 beds [7]. Health care professionals in the Gaza Strip are working hard to meet the health needs of their patients which causes physical and mental stress for them. Therefore, the midst of the pandemic, there should be a focus on the impact COVID-19 on health care workers' (HCW) safety, their willingness to continue to work [8] and on their psychological status.

Several studies were conducted to detect psychological impact of COVID-19 on several groups of the populations such as health care providers [9], particularly nurses [10, 11], general population [12-14], elderly [15, 16], children and adolescents [17], university students [18] and health care workers [19, 20].

In a study conducted by Vizheh, Qorbani [20], many HCW reported high prevalence of depression $(24.1 \%$,), anxiety (24.1\%) and stress (29.8\%). Furthermore, the study revealed that females, nurses, younger medical staff, front-line HCW and those working in areas with higher rates of infection reported more higher levels of all psychological symptoms than other HCW [20].

The first measure that Palestinian authorities undertook in dealing with Corona virus was establishing quarantine centers to quantize people returning to Gaza for 14 day. Following the community spread in late August, 2020, a decision for complete lock down of the Gaza Strip was made. Therefore, therefore, facilities where a big number of people gather such as mosques, schools and education facilities, universities, wedding halls were closed. Moreover, health services provided by hospitals and primary health care centers were limited. For already impoverished communities in the occupied Palestinian territories $(\mathrm{oPt})$, these dynamics form new burdens on caregivers mostly women [5].

Moreover, besides the anticipation and fear of contamination of corona virus, the protective measures of the Palestinian government mainly closure, guarantee and curfew add extra stress and psychological pressure on the nurses and their families. Therefore, this study aimed to assess the psychological impact of COVID-19 pandemic on Palestinian nurses residing in the Gaza Strip, Palestine.

\section{METHODS AND MATERIALS}

\subsection{Design, population, setting, and sampling}

A cross-sectional design was used in this study. The target population comprised of nurses employed by the Palestinian Ministry of Health in Gaza. Data were collected through and electronic questionnaire which was distributed to target population through social media (Facebook, Email, and WhatsApp applications). The total number of nurses working on the governmental health section is 2690 nurses. According to calculator.net, an online sample calculator (https://www.calculator.net/sample-size-calculator.html), a representative sample of 337 will be enough. In this study, a convenience sample of 424 nurses completed and submitted the electronic responses.

\subsection{Instrument}

An instrument composed from two parts was used in this study. The first part of the instrument included demographic information about participants such as gender, age, level of education, marital status, place of work, hospital and its departments, and others. Moreover, the demographic section included information related to years of experience, level of exposure and infection of COVID-19, and if the participants received training related to COVID-19 or not, ] availability of personal protective equipment, and if they have a history of a chronic disease.

The second part of the instrument comprised of the 7-item Generalized Anxiety Disorder Scale (GAD-7). The GAD-7 was developed by Toussaint, Hüsing [21] and it includes seven items based on seven core symptoms and inquires the frequency with which respondents suffered from these symptoms within the last two weeks prior to data collection. GAD-7 measures anxiety symptoms using a 4-point Likert scale ranging from zero to three, where $0=$ not at all, $1=$ several days, $2=$ over half the days and $3=$ almost every day, therefore, the total score will range from 0 to 21 . The GAD-7 showed to be valid and reliable [22,23] and it has demonstrated excellent internal consistency (Cronbach's a = $0.884)$ in this study.

\section{3 .Data Analysis}

The Statistical Package for Social Science (SPSS), version 22, was used to compute and analyze the data. Data was analyzed using descriptive statistics (mean, range, standard deviation, and percentage) and frequency distribution tables. ANOVA and t-test were used to examine statistical significance between differences of the means of different variables. Pearson correlations test was used to examine if there were any correlation between total score of GAD-7and some sociodemographic variables.

\section{4 Ethical Considerations}

Prior to conducting this research study, approval from the Research Ethics Committee at the Islamic University of 
Gaza was obtained. Participants were informed about the purpose of the study at the opening statement of the questionnaire and were assured that their participation is voluntary and that each one has the right to refuse to complete the questionnaire. Data were collected anonymously from all participants. Confidentiality and anonymity were maintained during data analysis and in the final report, the study results and recommendations will be distributed to the participants through social media applications.

\section{RESULTS}

\subsection{Characteristics of Participants}

Table 1: Socio-demographic characteristics of participants

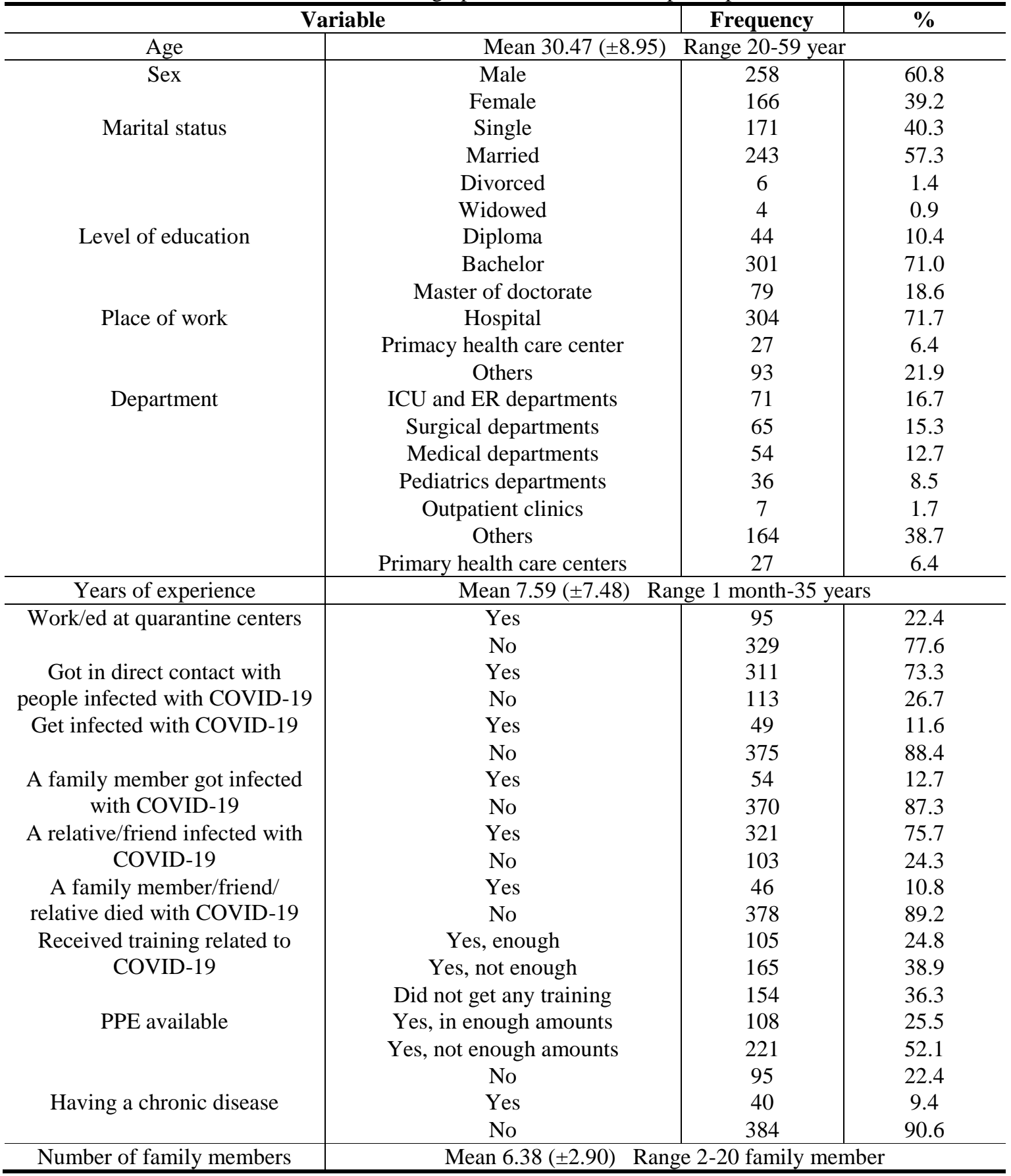

The above table depicts the characteristics of participants. The age of participants ranged between 20 and 59 years with a mean of $30.47( \pm 8.95)$. Most of the participants were males $(60.8 \%)$, married $(57.3 \%)$ and holding a bachelor degree in nursing $(71.1 \%)$. Most of the participants work at hospitals $(71.7 \%)$, at different departments, mainly at surgical departments (15.3\%) and Intensive Care Units (ICU) and Emergency Room (ER) departments (16.7\%). The years of experience ranged between one month (for those who were recently employed during the pandemic and 35 years 
with a mean of $7.59( \pm 7.48)$. While only $22.4 \%$ of the participants worked at quarantine centers designated to take care of infected/suspected cases of COVID-19, but a huge number of them (77.6\%) got in direct contact with infected people. Of all participants, $49(11.6 \%)$ got infected with the virus, $54(12.7 \%)$ reported that a family member was infected and $75.7 \%$ reported that a relative or a friend was infected with COVID-19. On the other hand, 46 (10.8\%) reported having a family member or a relative died due to COVID-19. Only $24.8 \%$ of the participants reported having adequate training related to COVID-19 and only 25.5\% reported having enough Personal Protective Equipment (PPE) available at their departments. Finally, only $40(9.4 \%)$ participants reported suffering from a chronic disease.

\subsection{Analysis of GAD-7}

Table 2 depicts the results for frequency, percentage, mean and standard deviation of GAD-7 items. The item "Feeling nervous, anxious, or on edge" had the highest mean $(1.52 \pm 0.94)$ while the item "Being so restless that it's hard to sit still" had the lowest mean $(0.81 \pm 0.89)$.

Table 2: Frequency, percentage, mean and standard deviation of GAD-7 items

\begin{tabular}{|c|c|c|c|c|c|c|}
\hline & $\begin{array}{l}\text { Not at } \\
\text { all sure }\end{array}$ & $\begin{array}{c}\text { Several } \\
\text { days }\end{array}$ & $\begin{array}{c}\text { Over half } \\
\text { the days }\end{array}$ & $\begin{array}{c}\text { Nearly } \\
\text { every day }\end{array}$ & & \\
\hline & $\begin{array}{c}\text { Freq. } \\
(\%)\end{array}$ & $\begin{array}{c}\text { Freq. } \\
(\%)\end{array}$ & Freq. (\%) & Freq. (\%) & Mean & SD \\
\hline $\begin{array}{c}\text { Feeling nervous, anxious, or on } \\
\text { edge }\end{array}$ & $\begin{array}{c}45 \\
(10.6 \%)\end{array}$ & $\begin{array}{c}202 \\
(47.6 \%)\end{array}$ & $90(21.2 \%)$ & $87(20.5 \%)$ & 1.52 & 0.94 \\
\hline $\begin{array}{c}\text { Not being able to stop or control } \\
\text { worrying }\end{array}$ & $\begin{array}{c}146 \\
(34.4 \%)\end{array}$ & $\begin{array}{c}179 \\
(42.2 \%)\end{array}$ & $71(16.7 \%)$ & $28(6.6 \%)$ & 0.96 & 0.88 \\
\hline $\begin{array}{l}\text { Worrying too much about } \\
\text { different things }\end{array}$ & $\begin{array}{c}92 \\
(21.7 \%)\end{array}$ & $\begin{array}{c}167 \\
(39.4 \%)\end{array}$ & $\begin{array}{c}101 \\
(23.8 \%)\end{array}$ & $64(15.1 \%)$ & 1.32 & 0.98 \\
\hline Trouble relaxing & $\begin{array}{c}84 \\
(19.8 \%)\end{array}$ & $\begin{array}{c}193 \\
(45.5 \%)\end{array}$ & $87(20.5 \%)$ & $60(14.2 \%)$ & 1.29 & 0.94 \\
\hline $\begin{array}{l}\text { Being so restless that it's hard to } \\
\text { sit still }\end{array}$ & $\begin{array}{c}191 \\
(45.0 \%)\end{array}$ & $\begin{array}{c}145 \\
(34.2 \%)\end{array}$ & $64(15.1 \%)$ & $24(5.7 \%)$ & 0.81 & 0.89 \\
\hline $\begin{array}{l}\text { Becoming easily annoyed or } \\
\text { irritable }\end{array}$ & $\begin{array}{c}85 \\
(20.0 \%)\end{array}$ & $\begin{array}{c}192 \\
(45.3 \%)\end{array}$ & $89(21.0 \%)$ & $58(13.7 \%)$ & 1.28 & 0.91 \\
\hline $\begin{array}{l}\text { Feeling afraid as if something } \\
\text { awful might happen }\end{array}$ & $\begin{array}{c}139 \\
(32.8 \%)\end{array}$ & $\begin{array}{c}157 \\
(37.0 \%)\end{array}$ & $76(17.9 \%)$ & $52(12.3 \%)$ & 1.10 & 0.99 \\
\hline
\end{tabular}

\subsection{Level of anxiety among participants}

According to the scoring system accompanied the GAD-7, scores of 5, 10, and 15 are taken as the cut-off points for mild, moderate and severe anxiety, respectively. According to these scoring cut-off points, results (table 3) revealed that about more than one third of participants $(150,35.4 \%)$ suffers from mild anxiety while 57 participants $(13.4 \%)$ shows signs and symptoms of sever anxiety.

Table 3: Level of anxiety among nurses

\begin{tabular}{c|c|c}
\hline & Percent & Frequency \\
\hline No anxiety & 27.6 & 117 \\
Mild anxiety & 35.4 & 150 \\
Moderate anxiety & 23.6 & 100 \\
Severe anxiety & 13.4 & 57 \\
\hline
\end{tabular}

\subsection{Factors influencing level of anxiety}

Pearson correlation did not show statistically significant correlations between total score of GAD-7 and age and number of family members. On the other hand, it showed a positive correlation between total score of GAD-7 and years of experience $(\mathrm{p}<0.001)$. Moreover, independent $\mathrm{t}$ test showed that there were statistically significant differences between total score of GAD-7 and some variables (table 4) including: sex ( $p=0.009)$, having a family member infected with COVID-19 ( $\mathrm{p}=0.041)$, a family member died with COVID-19 ( $\mathrm{p}=0.033)$ and getting in direct contact with people infected/ suspected to have COVID-19 $(\mathrm{p}=0.034)$

On the other hand, ANOVA test revealed that marital status $(\mathrm{p}=0.447)$, level of education $(\mathrm{p}=0.10)$, place of work $(\mathrm{p}=0.936)$, department $(\mathrm{p}=0.140)$, receiving training about COVID-19 $(\mathrm{p}=0.380)$ and having enough PPE $(\mathrm{p}=0.555)$ have no statistically significant differences among means of different groups. 
Table 4: Factors impacting level of anxiety among nurses

\begin{tabular}{|c|c|c|c|c|c|}
\hline \multicolumn{2}{|l|}{ Variable } & $\mathbf{N}$ & Mean & SD & P value \\
\hline Sex & Male & 258 & 7.75 & 5.13 & 0.009 \\
\hline & Female & 166 & 9.10 & 5.10 & \\
\hline Have a chronic disease & Yes & 40 & 8.95 & 5.03 & 0.387 \\
\hline & No & 384 & 8.21 & 5.17 & \\
\hline Infected with COVID-19 & Yes & 49 & 9.53 & 4.75 & 0.057 \\
\hline & No & 375 & 8.11 & 5.19 & \\
\hline Family member infected & Yes & 54 & 9.72 & 5.50 & 0.041 \\
\hline with COVID-19 & No & 370 & 8.07 & 5.08 & \\
\hline Relatives/friends infected & Yes & 321 & 8.32 & 5.14 & 0.765 \\
\hline with COVID & No & 103 & 8.15 & 5.25 & \\
\hline Family member died with & Yes & 46 & 9.98 & 5.64 & 0.033 \\
\hline COVID-19 & No & 378 & 8.07 & 5.06 & \\
\hline Work at quarantine & Yes & 95 & 8.17 & 4.95 & 0.814 \\
\hline centers & No & 329 & 8.31 & 5.22 & \\
\hline Get in direct contact with & Yes & 311 & 8.5981 & 5.14398 & 0.34 \\
\hline $\begin{array}{l}\text { people infected/ suspected } \\
\text { to have COVID-19 }\end{array}$ & No & 113 & 7.3982 & 5.11220 & \\
\hline
\end{tabular}

\section{DISCUSSION}

This study aimed to assess psychological impact of COVID-19 on Palestinian nurses employed by the Palestinian Ministry of Health in Gaza. Results revealed variant levels of anxiety among participants (table 3) with $23.6 \%$ of the participants having moderate level of anxiety and $13.4 \%$ having severe level. Such impact of COVID-19 is expected especially that this is the first experience for nurses in Gaze to confront a rapid spread of infectious diseases. Maben and Bridges [24] ensured that usually, nurses will have strong emotional reactions to the COVID-19 virus and it will elicit several emotional reactions including fear, anger, frustration, worries. These reactions mostly will affect nurse's work. Although, fear and anxiety are normal, but if they become more intense, they may result in that nurses will feel unable to care for their patients as they would have otherwise.

Levels of anxiety among nurses reported in this study are relatively high. Since there is a paucity of studies using GAD-7 to measure level of anxiety among nurses, comparison with similar studies was not possible. In line with the findings of this study, another two studies have reported high levels of psychological distress among nurses during the COVID-19 pandemic [10, 25]. 37.8\% of participants in Labrague and De los Santos [10] study found to have dysfunctional levels of anxiety. Also, a systematic review study reported a high prevalence of mental disturbances such as depression and anxiety among HCW during the COVID-19 pandemic [26]. On the other hand, findings of this study were in concordance with the results of other studies which measured the psychological impact during outbreaks of other infectious disease. These studies reported that nurses had experienced several types of mental distresses such as fear, anxiety, loneliness, sleep disorders, fatigue and other physical and health problems during previous epidemics of other infectious diseases such as H1N1 influenza MERS-Cov, SARS, Ebola[27-31].

There are many possible factors that might contribute to the high prevalence of anxiety among nurses in Gaza; including the exceptional conditions they live in the Gaza Strip. For example, Gaza suffers from siege imposed by Israel since 2006 with no free movement is possible in and out of the Gaza Strip. Following the 2014 war, movement of people and goods has been further restricted [32]. This is along the low salary which they receive in irregularly. The high risk to contract the Corona virus represent another factor to increase nurse's fear and anxiety since $75.7 \%$ of the participants had relatives and/or friends infected with COVID. The results of this study were supported by the results of another study which found that fear and anxiety increase when there is a risk for loved ones to get the infection [33].

In this study, age did not impact level of anxiety among nurses. These results go in line with the results reported by Labrague and De los Santos [10]. On the other hand, results reported by [34] showed that age had an impact on anxiety levels among participants; which could be related to the high mean of the age of the participants (40.84) compared to the mean of age of this study (30.47) and mean of age of participants (30.94) in Labrague and De los Santos [10] study.

Lack of adequate training related to COVID-19 was also a risk factor to increase anxiety among participants. The results of this study showed that $38.9 \%$ of the nurses did not receive enough training while $36.3 \%$ of them did not get any training. Finally, another factor that was reported by participants of this study and could be a factor to increasing their anxiety is lack of personal protective equipment (PPE), as $52.1 \%$ of the nurses in the study sample reported lack of PPE, while $22.4 \%$ of them reported that PPE were not available.

The high level of anxiety reported in this study should alert health policy makers since anxiety have many malicious 
consequences. In a study conducted by Shevlin, Nolan [35], results revealed that high levels of anxiety had several health consequences such as fatigue and gastrointestinal manifestations. Moreover, high level of anxiety had led to other mental consequences including depression and psychological distress [36, 37].

The results of this study reported inadequate training of nurses to combat COVID-19. This result is similar to earlier studies where many nurses reported inadequate preparedness to handle patients affected by infectious disease such as H1N1, Ebola and COVID-19 [10, 38, 39]. The results of this study assured the "need for nurses to be fully equipped with the required competencies in order to better handle and manage patients affected by disease outbreaks and in emergency situations" to enhance their resilience. Literature revealed that personal resilience impacts performance of health workers, their health and wellbeing [10,40]. Therefore; it is of especial concern for health policy makers to enhance nurses' resilience through proactive organizational measures. This could be achieved through social support and organizational support; especially that these measures are significantly associated with positive work outcomes (e.g. job engagement, job satisfaction, and work performance) and physical and mental health for nurses [40, 41]. Furthermore; studies revealed that positive attitudes in the workplace, improvement of infected staff, and controlling disease transmission among HCPs after implementing strict protective measures contributed to reducing their anxiety and fear [29]. Research has identified that healthcare professionals have requested five things from their employer during the COVID-19 pandemic: "hear me, protect me, prepare me, support me, and care for me" [42]. Hence; it is vital that measures aimed towards improving these elements are implemented in the workplace especially that nurses constitute the backbone of any health care system including the Palestinian health care system.

Moreover, since nurses are in the frontline for caring for COVID-19 patients and providing health care services, it is essential to implement measures to reduce their anxiety because dysfunctional anxiety levels were reported to be strong precursors of psychological distress, depression and other psychological disorders [36, 37].

\section{CONCLUSIONS AND IMPLICATIONS FOR PRACTICE}

The results of this study revealed high level of anxiety among nurses employed by the Palestinian Ministry of Health in Gaza. The high risk to get the infection due to getting in contact with infected patients is one of the major factors of nurse's fear and anxiety. They may have anticipatory anxiety to be infected through their contact with patients, friends, relatives and family members. Lack of adequate training related to COVID-19 and lack of personal protective equipment add extra stressors for the nurses. Siege, Israeli occupation, inadequate salaries and political conflicts are also ongoing stressors in the Palestinians live in Gaza.

It is recommended to providing training courses related to COVID-19 protection, personal protective equipment should be always available for all nurses, especially for nurses working in the hot areas of work. Moreover, tailoring psycho-social support programs as setting channels of one-to-one online or phone counseling for nurses may be effective to alleviate negative psychological effects and to enhance mental health of nurses.

\section{REFERENCES}

[1] McIntosh, K. Coronavirus disease 2019 (COVID-19): Epidemiology, virology, and prevention. 2020 22/12/2020 [cited 2020 25/12]; Available from: https://www.uptodate.com/contents/coronavirus-disease-2019-covid-19epidemiology-virology-and-prevention.

[2] Wu, Z. and J.M. McGoogan, Characteristics of and important lessons from the coronavirus disease 2019 (COVID19) outbreak in China: summary of a report of 72314 cases from the Chinese Center for Disease Control and Prevention. Jama, 2020.

[3] Ministy of Health. Daily report about Coronal Virus (COVID 19): 6/3/2020. 2020 6/3/2020; Available from: http://site.moh.ps/index/ArticleView/ArticleId/4844/Language/ar.

[4] One World Nations Online. State of Palestine: Palestinian territories. 2020 28/12/2020]; Available from: https://www.nationsonline.org/oneworld/palestinian territory.htm.

[5] Foqahaa, N., S. , M. Barghouti, and S. Said. COVID-19: Gendered Impacts of the Pandemic in Palestine and Implications for Policy and Programming: Findings of a Rapid Gender Analysis of COVID-19 in Palestine. 2020 [cited 2020 27/12]; Available from: https://www2.unwomen.org//media/field\%20office\%20palestine/attachments/publications/2020/4/covid\%2019\%20$\% 20$ un\%20women\%20rapid\%20gender\%20analysis.pdf?la=en\&vs=4626.

[6] BBC NEWS. Covid: Gaza health system 'days from being overwhelmed. 2020 [cited 2020 14/12/2020]; Available from: https://www.bbc.com/news/world-middle-east-55035955.

[7] Made for Minds. Coronavirus infections skyrocket in Gaza Strip. 2020 [cited 2020 15/12]; Available from: https://www.dw.com/en/coronavirus-infections-skyrocket-in-gaza-strip/a-55761490.

[8] Schwartz, J., C.-C. King, and M.-Y. Yen, Protecting healthcare workers during the coronavirus disease 2019 (COVID-19) outbreak: lessons from Taiwan's severe acute respiratory syndrome response. Clinical Infectious Diseases, 2020. 
[9] Tan, B.Y., et al., Psychological impact of the COVID-19 pandemic on health care workers in Singapore. Annals of Internal Medicine, 2020.

[10] Labrague, L.J. and J.A.A. De los Santos, COVID-19 anxiety among front-line nurses: Predictive role of organisational support, personal resilience and social support. Journal of nursing management, 2020. 28(7): p. 1653-1661.

[11] Hendy, A., et al., Predictive factors affecting stress among nurses providing care at COVID-19 isolation hospitals at Egypt. Nursing open, 2020.

[12] Duan, L. and G. Zhu, Psychological interventions for people affected by the COVID-19 epidemic. The Lancet Psychiatry, 2020. 7(4): p. 300-302.

[13] Rossi, R., et al., COVID-19 pandemic and lockdown measures impact on mental health among the general population in Italy. Frontiers in Psychiatry, 2020. 11.

[14] Serafini, G., et al., The psychological impact of COVID-19 on the mental health in the general population. 2020 , Oxford University Press.

[15] Meng, H., et al., Analyze the psychological impact of COVID-19 among the elderly population in China and make corresponding suggestions. Psychiatry research, 2020. 289: p. 112983.

[16] Yang, Y., et al., Mental health services for older adults in China during the COVID-19 outbreak. The Lancet Psychiatry, 2020. 7(4): p. e19.

[17] Li, S., et al., Analysis of influencing factors of anxiety and emotional disorders in children and adolescents during home isolation during the epidemic of novel coronavirus pneumonia. Chinese Journal of Child Health, 2020. 28(3): p. 1-9.

[18] Wang, Z., et al., Prevalence of anxiety and depression symptom, and the demands for psychological knowledge and interventions in college students during COVID-19 epidemic: A large cross-sectional study. Journal of affective disorders, 2020. 275: p. 188-193.

[19] Sun, N., et al., A qualitative study on the psychological experience of caregivers of COVID-19 patients. American journal of infection control, 2020. 48(6): p. 592-598.

[20] Vizheh, M., et al., The mental health of healthcare workers in the COVID-19 pandemic: A systematic review. Journal of Diabetes \& Metabolic Disorders, 2020: p. 1-12.

[21. Toussaint, A., et al., Sensitivity to change and minimal clinically important difference of the 7-item Generalized Anxiety Disorder Questionnaire (GAD-7). Journal of affective disorders, 2020. 265: p. 395-401.

[22] Cao, W., et al., The psychological impact of the COVID-19 epidemic on college students in China. Psychiatry research, 2020: p. 112934.

[23] Spitzer, R.L., et al., A brief measure for assessing generalized anxiety disorder: the GAD-7. Archives of internal medicine, 2006. 166(10): p. 1092-1097.

[24] Maben, J. and J. Bridges, Covid-19: Supporting nurses' psychological and mental health. Journal of clinical nursing, 2020.

[25] Amin, S., The psychology of coronavirus fear: Are healthcare professionals suffering from corona-phobia? International Journal of Healthcare Management, 2020: p. 1-8.

[26] Pappa, S., et al., Prevalence of depression, anxiety, and insomnia among healthcare workers during the COVID19 pandemic: A systematic review and meta-analysis. Brain, behavior, and immunity, 2020.

[27] Chung, B.P.M., et al., SARS: caring for patients in Hong Kong. Journal of clinical nursing, 2005. 14(4): p. 510517.

[28] Kim, Y., Nurses' experiences of care for patients with Middle East respiratory syndrome-coronavirus in South Korea. American journal of infection control, 2018. 46(7): p. 781-787.

[29] Khalid, I., et al., Healthcare workers emotions, perceived stressors and coping strategies during a MERS-CoV outbreak. Clinical medicine \& research, 2016. 14(1): p. 7-14.

[30] Liu, C., et al., Sources and symptoms of stress among nurses in the first Chinese anti-Ebola medical team during the Sierra Leone aid mission: A qualitative study. International journal of nursing sciences, 2019. 6(2): p. 187191.

[31] Honey, M. and W.Y. Wang, New Zealand nurses perceptions of caring for patients with influenza A (H1N1). Nursing in Critical Care, 2013. 18(2): p. 63-69.

[32] UN Office for the Coordination of Humanitarian Affairs. Gaza Strip. 2020 [cited 2020 28/12]; Available from: https://www.ochaopt.org/location/gaza-strip.

[33] Mertens, G., et al., Fear of the coronavirus (COVID-19): Predictors in an online study conducted in March 2020. Journal of Anxiety Disorders, 2020: p. 102258.

[34] McCleskey, J. and D. Gruda, Risk-taking, resilience, and state anxiety during the COVID-19 pandemic: A coming of (old) age story. Personality and Individual Differences, 2020: p. 110485.

[35] Shevlin, M., et al., COVID-19-related anxiety predicts somatic symptoms in the UK population. British Journal of Health Psychology, 2020.

[36] Mo, Y., et al., Work stress among Chinese nurses to support Wuhan in fighting against COVID-19 epidemic. Journal of nursing management, 2020. 
[37] Teles, M.A.B., et al., Psychosocial work conditions and quality of life among primary health care employees: a cross sectional study. Health and Quality of Life Outcomes, 2014. 12(1): p. 72.

[38] Baduge, M.S.P., J. Morphet, and C. Moss, Emergency nurses' and department preparedness for an ebola outbreak: A (narrative) literature review. International emergency nursing, 2018. 38: p. 41-49.

[39] McMullan, C., G.D. Brown, and D. O'Sullivan, Preparing to respond: Irish nurses' perceptions of preparedness for an influenza pandemic. International emergency nursing, 2016. 26: p. 3-7.

[40] Labrague, L.J., et al. Perceptions of organizational support and its impact on nurses' job outcomes. in Nursing forum. 2018. Wiley Online Library.

[41] Hu, S.H., et al., Social support and factors associated with self-efficacy among acute-care nurse practitioners. Journal of clinical nursing, 2018. 27(3-4): p. 876-882.

[42] Shanafelt, T., J. Ripp, and M. Trockel, Understanding and addressing sources of anxiety among health care professionals during the COVID-19 pandemic. Jama, 2020. 323(21): p. 2133-2134. 